\title{
DIFICULDADES E DESAFIOS PARA O ENSINO DE DANÇA, NAS AULAS DE EDUCAÇÃO FíSICA, NO ENSINO FUNDAMENTAL II
}

DOI 105902/0102830817375

Data de submissão: 19/03/2015

Data de aceite: 01/06/2015

\begin{abstract}
Edsanra Dutra Da Cruz Faculdade Católica Rainha Da Paz

Márcia Cristina Rodrigues Da Silva Coffani Coffani Faculdade De Educação Física - Universidade Federal De Mato Grosso marciacoffani@hotmail.com
\end{abstract}

\begin{abstract}
Resumo
Investigou-se as dificuldades pedagógicas que professores de Educação Física enfrentam para ensinar dança, no Ensino Fundamental II, em escolas estaduais de S. J. dos Quatro Marcos/MT. O estudo é qualitativo-descritivo. Aplicou-se roteiro de entrevista semiestruturada com três professores, organizado em: a) perfil pessoal; b) formação profissional; c) atuação profissional; d) o ensino de dança. Encontraram-se dados sobre a formação profissional dos professores; a presença de estereótipos sobre a dança como elemento da formação educacional; e as dificuldades pedagógicas. A investigação contribuiu para discussão da dança numa perspectiva emancipatória, que ultrapasse a dimensão técnicaprocedimental da aprendizagem do movimento.
\end{abstract}

PALAVRAS-CHAVE: Dança. Educação Física. Ensino Fundamental II. 


\section{INTRODUÇÃO}

O artigo é resultado de uma pesquisa monográfica que investigou as dificuldades pedagógicas, que os professores enfrentam para desenvolver o ensino de dança na escola, como conteúdo das aulas de Educação Física, no Ensino Fundamental II, a partir da realidade das escolas da rede estadual de ensino, no município de São José dos Quatro Marcos - MT.

A Educação Física é uma prática pedagógica que, no âmbito escolar, tematiza formas de atividades expressivas corporais como jogo, esporte, dança, ginástica (SOARES et al., 1992). Essas práticas têm em comum a representação corporal de diversos aspectos da cultura humana, entendidas como $[\tilde{n} . .$.$] atividades que ressignificam a cultura corporal$ humana e o fazem utilizando ora uma intenção mais próxima do caráter lúdico, ora mais próxima do pragmatismo e da objetividadeò(BRASIL, 1998, p. 28).

A dança consiste num dos conteúdos do currículo da Educação Física, inclusa no Bloco das Atividades Rítmicas e Expressivas, tendo como principal característica a expressão corporal. Há uma diversidade de aprendizagens possíveis por meio da dança, em especial, o conhecimento da cultura rítmica dos povos contribuindo para formação social e cultural do aluno, permitindo discussões que inclui a valorização da identidade do sujeito (BRASIL, 1998).

No Ensino Fundamental II, o ensino de dança inclui o conhecimento e aprendizagem de:

Equilíbrio entre a instrumentalização e a liberação do gesto espontâneo (nem só técnica, nem só movimento pelo movimento; contextualizar a instrumentalização sempre que for conveniente, não só para apresentações) percepção do seu ritmo próprio; percepção do ritmo grupal; desenvolvimento da noção espaço/tempo vinculada ao estímulo musical e ao silêncio com relação a si mesmo e ao outro; compreensão do processo expressivo relacionando o código individual de cada um com o coletivo (mímicas individuais, representações de cenas do cotidiano em grupo, danças individuais, pequenos desenhos coreográficos em grupo); percepção dos limites corporais na vivência dos movimentos fluidos e alongados, criando oportunidade de transcender as limitações (BRASIL, 1998, p. 98).

Marques (2007) alerta que há uma desvalorização do ensino de dança na escola, que pode ser motivada pela presença de uma tendência tecnicista e racionalista, que desvaloriza o ensino das habilidades artísticas e expressivas aos alunos. Percebe-se que propostas pedagógicas que envolvem o ensino de dança e que trabalhem seus aspectos criativos, 
portanto, imprevisíveis e indeterminados, ainda r̃assustamò aqueles que aprenderam e são regidos pela didática tradicional. $E$, que permanecem advogando por um ensino r̃garantidoò (sabemos onde vamos chegar), r̃conhecidoò(já temos experiências de muitos anos na área), r̃determinado e pré-planejadoò(não haverá surpresas).

Além disso, o [....] ensino da dança ainda está coberto de preconceitos onde professores tentam dar outros nomes para a dança como expressão corporal, educação de movimentoò(MARQUES, 2007, p. 20).

Esses aspectos diagnosticados durante o estágio curricular supervisionado, é que motivaram a proposição da pesquisa, que investigou: as dificuldades pedagógicas enfrentadas pelos professores para o ensino de dança no Ensino Fundamental II, nas aulas de Educação Física, em escolas da rede estadual de ensino de São José dos Quatro Marcos - MT. De forma específica, foi pesquisado o perfil pessoal e da formação profissional dos professores; as condições de atuação profissional na escola pública, que implicam sobre as possibilidades de ensino de dança como conteúdo das aulas de Educação Física; e a visão dos professores sobre a importância e função pedagógica desse conteúdo na formação do aluno da Educação Básica.

\section{METODOLOGIA}

A pesquisa é de abordagem qualitativa com tendência descritiva. Os participantes do estudo foram os professores de Educação Física, do Ensino Fundamental II, que atuam na rede estadual de ensino, tanto na zona rural como urbana, do município de São José dos Quatro Marcos - MT.

Para realizar a pesquisa foi encaminhada Carta Convite às escolas, Termo de Consentimento Livre e Esclarecido aos professores de Educação Física, que no ano de 2011, atuaram no Ensino Fundamental II, ministrando as aulas de Educação Física, em escolas da rede estadual de ensino e Termo de Autorização para uso de imagem em fotografias, filmagens e gravações de voz, dos sujeitos da pesquisa.

Adotou-se como instrumento para levantamento de dados a aplicação de um roteiro de entrevista semi-estruturado, validados por três professores da área, composto de: Parte I Perfil Pessoal; Parte II - Formação profissional; Parte III - Atuação profissional; Parte IV - O ensino de dança na Educação Física Escolar. 
As entrevistas foram realizadas com três professores, denominados de S1, S2 e S3, sendo duas professoras com 22 e 29 anos e um professor com 26 anos, escolhidos a partir do contato com a Assessoria Pedagógica do município de São José dos Quatro Marcos MT, no espaço da escola e no horário das aulas de Educação Física ou no local de moradia do professor, caso fosse a sua escolha.

\section{ANÁLISE E DISCUSSÃO DOS RESULTADOS}

O quadro 1 apresenta a síntese dos dados pessoais dos professores de Educação Física envolvidos neste trabalho, que revelam a base da sua formação inicial e atuação profissional na área:

\begin{tabular}{|l|l|l|l|l|l|}
\hline $\begin{array}{l}\text { SUJEITO } \\
\text { DA } \\
\text { PESQUISA }\end{array}$ & $\begin{array}{l}\text { CURSO DE } \\
\text { FORMAÇÃO }\end{array}$ & $\begin{array}{l}\text { CONCLUSÃO DO ENSINO } \\
\text { SUPERIOR }\end{array}$ & $\begin{array}{l}\text { IES DE } \\
\text { FORMAÇÃO }\end{array}$ & $\begin{array}{l}\text { VÍNCULO } \\
\text { EMPREGATÍCIO }\end{array}$ & $\begin{array}{l}\text { TEMPO DE ATUAÇÃO } \\
\text { PROFISSIONAL }\end{array}$ \\
\hline S1 & Licenciatura & 2010 & Privada & Interino \\
\hline S2 & Licenciatura & 2009 & Privada & Interino & 02 anos \\
\hline S3 & Bacharelado & 2009 & Privada & Interino \\
\hline
\end{tabular}

Quadro 1 - Formação Profissional dos Professores de Educação Física, que atuam no Ensino Fundamental II, na rede estadual de São José dos Quatro Marcos - MT.

Nota: Construção das autoras.

Os professores entrevistados estão em início de carreira profissional e se formaram em cursos superiores que se constituíram após as reformulações curriculares de 2002. A partir de 2000, em Mato Grosso, ocorreu a expansão dos cursos de Educação Física, tanto na capital como no interior do estado. Em 2012, o estado teve em funcionamento cerca de 12 cursos de graduação em Educação Física, se dividindo em bacharelado e licenciatura, na capital e demais localidades do estado, mantidos por IES públicas (UFMT e UNEMAT) e particulares (UNIC, UNIVAG, FASIPE, FCARP, UNED, entre outras).

A formação em Educação Física no Brasil foi tensionada com a recente instauração de cursos de licenciatura e bacharelado a partir de 2004. Há uma divisão na formação de sujeitos na área da Educação Física, ora voltada para o bacharelado com atuação prioritária para campos de atuação profissional que não seja o escolar, e o licenciado cujo campo profissional é a escola.

David (2002) explica que esta área de conhecimento recebe um tratamento diferenciado na formação acadêmica e profissional, por se tratar de uma área demarcada por uma prática pedagógica, científica e social, de natureza interdisciplinar, e que a sociedade 
reconhece que as intervenções profissionais ocorrem historicamente, sob a forma de docência, em diversos lugares e tempos sociais específicos.

As diferenças entre a formação do licenciado e bacharel em Educação Física residem, principalmente, na falta de disciplinas pedagógicas e práticas curriculares que oportunizem a orientação do planejamento e intervenção na escola. O bacharel em Educação Física não é preparado para atuação escolar. Contudo, em localidades em que há demanda do professor de Educação Física, pode vir a ocorrer a contratação do bacharel em Educação Física, na falta do licenciado. Fato este, que gera muita estranheza e preocupação sobre como será encaminhado o ensino da Educação Física na escola.

A pesquisa investigou como os professores percebiam a sua preparação profissional com base na formação inicial para o ensino de dança, como conteúdo das aulas de Educação Física, no Ensino Fundamental II, organizando suas respostas no quadro 2, abaixo:

\begin{tabular}{|l|l|}
\hline SUJEITO DA PESQUISA & RESPOSTAS \\
\hline S1 & Teve a matéria sobre dança, eu aprendi algumas questões de movimento corporal [sic]. \\
\hline S2 & Sim, aprendemos a prática de como ensinar dança [sic]. \\
\hline S3 & Na grade não teve o conteúdo Dança [sic]. \\
\hline
\end{tabular}

Quadro 2 - Preparação Profissional dos professores de Educação Física, que atuam no Ensino Fundamental II, na rede estadual de ensino de São José dos Quatro Marcos - MT, em relação ao ensino de Dança.

Nota: Construção das autoras.

A formação de professores é um ponto crítico, no que diz respeito ao ensino de dança na escola e nas aulas de Educação Física. Marques (2007, p. 21/22) comenta a visão ingênua que se tem a respeito do ensino de dança e alguns dos preconceitos existentes em relação à dança. Na grande maioria dos casos, professores não sabem exatamente o que, como ou até mesmo o porquê de ensinar a dança na escola.

Percebeu-se que em relação às professoras S1 e S2, que S3 não apresenta na sua formação profissional, os conhecimentos ou experiências com os elementos básicos de organização do processo de ensino de dança, como conteúdo curricular da Educação Física Escolar. Neste caso, se avalia que não há a garantia da presença e do ensino de dança na escola.

Segundo as orientações curriculares do Ensino Fundamental II (BRASIL, 1998), a Educação Física é entendida como uma área que trata de um tipo de conhecimento, denominado cultura corporal de movimento, que tem como temas o jogo, a ginástica, o esporte, a dança, a capoeira e outras temáticas, que estabeleçam relações com a cultura 
corporal de movimento e influenciam a compreensão do contexto histórico, social e cultural pelos alunos.

Este documento ao apresentar a concepção de cultura corporal de movimento amplia a contribuição da Educação Física Escolar para o exercício da cidadania, na medida em que, tomando seus conteúdos e as capacidades que se propõe a desenvolver como produtos socioculturais, afirma como direito de todos, o acesso e a participação no processo de aprendizagem (BRASIL, 1998).

O ensino de dança se apresenta incluso ao Bloco de Conhecimentos, denominado de Atividades Rítmicas e Expressivas, com a função de oportunizar a ñ...] expressão e comunicação por meio dos gestos na presença de ritmos, sons e da música na construção da expressão corporalò (BRASIL, 1998, p. 71), podendo se manifestar pela vivência de dança, mímicas e brincadeiras cantadas.

Marques (2007) relata que a escola teria, assim, o papel não de ŕsoltarò ou de ñeproduzirò mas de ñnstrumentalizaròe de r̃construiròconhecimentos em/por meio da dança com os alunos, pois é uma forma de conhecimento essencial para a educação do ser social.

As professoras S1 e S2 informam que receberam na formação inicial, conhecimentos sobre o planejamento e o ensino de dança na escola. Contudo, não têm muita clareza ou segurança para dizerem com maior profundidade pedagógica, como se organiza o processo de aprendizagem do aluno em relação à dança nas aulas de Educação Física. Suspeitou-se de uma incipiente formação na graduação, que não qualifica o professor para o trato pedagógico com a dança no currículo escolar.

Uma inadequada formação em dança, que em muitos casos é restrita a uma única disciplina do curso de graduação, com carga horária incipiente, o que não possibilita o aprofundamento necessário de conhecimentos e experiências com o ensino de dança. Como também, a inexistência de ações de extensão nos cursos de graduação, que possam ampliar as experiências do ñuturo professorò Podem ser apontadas como obstáculos para o ensino de dança nas aulas de Educação Física, no Ensino Fundamental, de forma que o professor tem optado por oferecer ao aluno, as tradicionais práticas esportivas.

Darido e Rangel (2005, p. 27) criticam a postura profissional docente quando este sujeito responsável pela formação de tantos outros sujeitos, restringe a sua prática pedagógica ao ensino de modalidades esportivas clássicas, dando prioridade ao futebol, apesar de ao longo da formação acadêmica ter recebido orientações e conhecimentos sobre atividade rítmicas e expressivas, cultura corporal e outros. 
Esses aspectos revelam a importância do r̃engajamentoòdo professor em programas de formação continuada na área de formação, a fim de que possa se manter atualizado para o desempenho da função docente. Barros (2002 apud PICCOLI; MENEZES, 2006) alerta que a formação continuada em Educação Física, visa atender à necessidade do profissional em entender a natureza dinâmica do conhecimento especializado e obter a competência necessária para o desenvolvimento intelectual e profissional, de forma autônoma e permanente. $\mathrm{O}$ que implica em compreender que o processo de qualificação profissional é constante e inacabado.

No quadro 3 são apresentados as respostas dos professores referentes aos conhecimentos que fundamentam suas práticas pedagógicas para o ensino de dança, nas aulas de Educação Física, no Ensino Fundamental II:

\begin{tabular}{|l|l|}
\hline SUJEITO DA PESQUISA & RESPOSTAS \\
\hline S1 & Eu não tenho outros conhecimentos que possa me ajudar na prática pedagógica [sic]. \\
\hline S2 & Pesquisa, eu pesquiso sobre a dança por que eu dou aula de aeróbica [sic]. \\
\hline S3 & Como na grade não teve o conteúdo Dança, na prática a gente não realiza [sic]. \\
\hline
\end{tabular}

Quadro 3 - Conhecimentos que fundamentam as práticas pedagógicas dos professores de Educação Física, no Ensino Fundamental II, na rede estadual de São José dos Quatro Marcos ï MT.

Nota: Construção das autoras.

Neste trabalho, se entende a Educação Física como uma área de conhecimento da cultura corporal de movimento e a Educação Física Escolar como uma disciplina que introduz e integra o aluno na cultura corporal de movimento, formando o cidadão que vai produzi-la, reproduzi-la e transformá-la, instrumentalizando-o para usufruir dos jogos, dos esportes, das danças, das lutas e das ginásticas, em benefício do exercício crítico da cidadania e da melhoria da qualidade de vida (BRASIL, 1998).

As orientações curriculares (BRASIL, 1998) destacam que cada uma dessas modalidades corporais (jogo, esporte, dança, ginástica e luta) têm benefícios humanos e inúmeras possibilidades de utilização como instrumentos de comunicação, expressão de sentimentos e emoções, de lazer e de manutenção e melhoria da saúde. Assim, os conteúdos das aulas de Educação Física não podem ser f̂́rutosò exclusivos da escolha pessoal do professor, que incorre em erro ao escolher aquilo que julga ser melhor para si e para o aluno, a partir do domínio procedimental de conhecimentos que possui.

O professor S3 parece se ressentir da formação profissional cursada por ele, apresentando dificuldades para lidar com o ensino de dança no currículo escolar. Percebe-se que há uma opção por îsilenciarò o ensino desse conteúdo do que procurar conhecer, 
preparar e encontrar outras formas de capacitação profissional para o ensino desse conteúdo, nas aulas de Educação Física.

Destaca-se que a fala da professora S2, que apresenta um perfil de professora pesquisadora da sua própria prática pedagógica. Este fato, justifica a importância de ações de iniciação científica na formação inicial, principalmente, nos cursos de formação docente, a fim de que o professor seja capaz de analisar, rever e intervir sobre a realidade de ensino em que se insere com autonomia e responsabilidade.

A pesquisa tem fundamental importância para o redimensionamento da prática do professor, sempre pedagógica e imbuída de intencionalidades nos diferentes contextos. Ressalta-se que o processo de formação docente deve assumir a responsabilidade pela abertura dos processos de pesquisa como metodologia de ensino, que compactuem com uma formação de qualidade do îuturo professorò consubstanciada pelas diferentes vivências de conhecimentos e experiências ao longo da formação, entre elas, ̃̃o fazer pesquisaò

Independentemente das condições de formação e atuação profissional na escola, foi percebido que faltam aos professores de Educação Física conhecimentos sobre referenciais teórico-metodológicos, que orientam o exercício da prática pedagógica. Assim, estes ñesistemòou r̃silenciamòo ensino de dança na escola, por justamente, não saberem propor e conduzir o processo de ensino-aprendizagem do aluno.

O quadro 4 apresenta a importância do ensino de dança, segundo os professores de Educação Física, que atuam no Ensino Fundamental II, a saber:

\begin{tabular}{|l|l|}
\hline SUJEITO DA PESQUISA & RESPOSTAS \\
\hline S1 & $\begin{array}{l}\text { Eu acredito que seja expressão corporal porque através da dança a pessoa consegue se expressar melhor, a } \\
\text { coordenação motora direita esquerda também [sic]. }\end{array}$ \\
\hline S2 & Coordenação Motora [sic]. \\
\hline S3 & $\begin{array}{l}\text { O papel do ensino dança para o ensino fundamental é muito importante pois oferece bastante } \\
\text { desenvolvimento de hábitos saudável para os alunos. Eles podem também prevenir no futuro doenças e } \\
\text { também ajuda muito na coordenação motora e no equilíbrio do aluno além das habilidades diversas nas } \\
\text { atividades [sic]. }\end{array}$ \\
\hline
\end{tabular}

Quadro 4 - A importância da dança nas aulas de Educação Física, do Ensino Fundamental II, na rede estadual de São José dos Quatro Marcos - MT.

Nota: Construção das autoras.

Brasileiro (2002, p. 10) explica que a conceituação do que seja dança é organizada em dois eixos conceituais, de forma que o $\tilde{n}$.... primeiro apresenta-a como movimento que fortalece, coordena, etc., e, com isso, ajuda a todas as atividades da Educação Física; enquanto o segundo apresenta-a como expressão cultural de um povoò Os professores envolvidos nesta pesquisa trataram a dança na perspectiva de possibilidade motora, excluindo suas contribuições para formação cultural, social e humana do sujeito. 
Exige-se a compreensão dança como produção, e também, produto do homem em suas relações como o mundo e que explicita diferentes relações na sua constituição (BRASILEIRO, 2002). O que significa compreender as ações motoras em dança como repletas de sentimentos, que expressam desejos e emoções, cunhadas de significados orientados e produzidos pela vida em comunidade. Assim, como uma forma de representação cultural do povo, de seus hábitos, costumes, crenças e mitos.

Strazzacappa (2001, p. 69) comenta que ñA dança no espaço escolar busca o desenvolvimento não apenas das capacidades motoras das crianças e adolescentes, como de suas capacidades imaginativas e criativasò Diz ainda que, o tratamento dado às atividades de dança se diferenciam daquelas normalmente propostas pela Educação Física, pois não caracterizam o corpo da criança como um apanhado de alavancas e articulações do tecnicismo esportivo, nem apresentam um caráter competitivo, comumente presente nos jogos desportivos. Diferentemente destas perspectivas, as atividades com dança enfocam as possibilidades do corpo expressar [i...] suas emoções e estas podem ser compartilhadas com outras crianças que participam de uma coreografia de grupoò(STRAZZACAPPA, 2001, p. 71).

O quadro 5 apresenta os objetivos do ensino de dança, no Ensino Fundamental II, segundo os professores participantes desta pesquisa:

\begin{tabular}{|c|c|}
\hline SUJEITO DA PESQUISA & RESPOSTAS \\
\hline S1 & $\begin{array}{l}\text { Não é bem isso que a gente vê na prática mas a importância é da criança se conhecer também, auto- } \\
\text { conhecimento por questão de movimento de aprimorar o movimento da criança de se expressar também } \\
\text { [sic]. }\end{array}$ \\
\hline S2 & $\begin{array}{l}\text { Eu acho que pode ajudar eles a compreender mais um ao outro interagir ficar mais amigável, tentar ser mais } \\
\text { amigo, ajudar [sic]. }\end{array}$ \\
\hline S3 & $\begin{array}{l}\text { Como nas aulas de Educação Física não tem o conteúdo dança, a gente não aplica mas, como eu falei é } \\
\text { bem importante para ajudar o aluno na sua formação na escola [sic]. }\end{array}$ \\
\hline
\end{tabular}

Os professores S1 e S2 relacionam como objetivos para o ensino de dança, nas aulas de Educação Física, no Ensino Fundamental II, a possibilidade de autoconhecimento e interação social entre os alunos. Essas são metas implícitas e subentendidas dentre os objetivos apontados nas orientações curriculares para o ensino de Educação Física, no Ensino Fundamental II. Contudo, os professores não conseguem apontar objetivos mais claros, que justifiquem o ensino de dança, como conteúdo das aulas de Educação Física, no Ensino Fundamental II, nem mesmo apresentam conhecimento do que as orientações curriculares propõem: 
Compreensão dos aspectos histórico-sociais das danças.

Percepção do ritmo pessoal.

Percepção do ritmo grupal.

Desenvolvimento da noção espaço/tempo vinculada ao estímulo musical e ao silêncio com relação a si mesmo e ao outro.

Exploração de gestos e códigos de outros movimentos corporais não abordados nos outros blocos.

Compreensão do processo expressivo partindo do código individual de cada um para o coletivo (mímicas individuais, representações de cenas do cotidiano em grupo, danças individuais, pequenos desenhos coreográficos em grupo).

Percepção dos limites corporais na vivência dos movimentos rítmicos e expressivos.

Predisposição a superar seus próprios limites nas vivências rítmicas e expressivas.

Vivências das danças folclóricas e regionais, compreendendo seus contextos de manifestação (carnaval, escola de samba e seus integrantes, frevo, capoeira, bumba-meu-boi etc.).

Reconhecimento e apropriação dos princípios básicos para construção de desenhos coreográficos e coreografias simples.

Vivência da aplicação dos princípios básicos na construção de desenhos coreográficos.

Vivência das manifestações das danças urbanas mais emergentes e compreensão do seu contexto originário.

Vivência das danças populares regionais, nacionais e internacionais e compreensão do contexto sociocultural onde se desenvolvem (BRASIL, 1998, p. 78).

Gariba e Franzoni (2007, p. 159) entendem que o fundamental é compreender a:

[...] dança como uma linguagem que, para além de permear o processo de produção do conhecimento e a inserção da práxis social, prioriza não só esse processo de construção, mas também os resultados dele advindos, remetendo-os a momentos preciosos, capazes de despertar a consciência crítica de quem os vivencia.

O quadro 6 apresenta a presença do ensino do conteúdo dança, no currículo da Educação Física, no Ensino Fundamental II:

\begin{tabular}{|l|l|}
\hline $\begin{array}{l}\text { SUJEITO DA } \\
\text { PESQUISA }\end{array}$ & RESPOSTAS \\
\hline S1 & Não como principal atividade, a maioria das vezes só as meninas que fazem e não são todos também [sic]. \\
\hline S2 & $\begin{array}{l}\text { Eu trabalhei um ano só na escola, eu não tive muita dificuldade não, mas só com as meninas com os meninos não deu } \\
\text { certo [sic]. }\end{array}$ \\
\hline S3 & Não, não é trabalhada [sic]. \\
\hline
\end{tabular}

Quadro 6 ï A presença do ensino de dança, na Educação Física, no Ensino Fundamental II, na rede estadual de São José dos Quatro Marcos ï MT.

Nota: Construção das autoras.

As ñalasòdos professores mostram que esse conteúdo é îsilenciadoòno cotidiano das aulas de Educação Física. Marques (2007) aponta que a dança é trabalhada na escola, 
muitas vezes, para apresentações em festinhas de final de ano. A autora comenta, que outras formas de presença da dança na escola, se ligam aos discursos de que a đ....] dança na escola é f̂bom para relaxarế, ñpara soltar emoçõesò rexpressar-se espontaneamenteò (MARQUES, 2007, p. 23). Registra ainda que, ñ...] não são poucos os diretores que querem atividades de dança na escola para r̃conter a agressividadeò ou rácalmarò os alunosò (MARQUES, 2007, p. 23).

Revela-se uma concepção e uso da dança de perspectiva utilitarista, como ñ...] um ótimo recurso para r̃se esquecer dos problemasò(esfriar a cabeça) e, para usar um termo em voga, ñprevenir contra o stressò (MARQUES, 2007, p. 23). Ou, como um instrumento, que serve somente ao propósito de ñrabalhar a coordenação motoraò(MARQUES, 2007, p. 23), conforme anteriormente afirmado pelos professores participantes desta pesquisa.

As f̂́alasòdos professores, ainda revelam, a presença da dança na escola como uma prática destinada ao gênero feminino. Strazzacappa (2001, p. 74) registra que, ĩEm algumas escolas, os estagiários são obrigados a chamarem o trabalho de rexpressão corporalò pois se o nome r̃dançaòaparece, muitos meninos se recusam a participar da atividade por não serem ñmulherzinhasò[sic]ò(STRAZZACAPA, 2001, p. 74).

Segundo Marques (2007) falar de preconceitos pode parecer coisa do passado, mas o ensino de dança, ainda está recoberto de ideias de preconceitos em relação a sua natureza, isso leva muitos professores atribuírem outros denominações às atividades de dança, como: rexpressão corporalò rãrte e criação@̣̂ ñmovimento e criaçãoò

Marques (2007) comenta que não são poucos os pais de alunos (sexo masculino), e os próprios alunos que ainda consideram dança r̃ oisa de mulherò Para a autora, em um país como o nosso, por que será que a dança enfrenta tantos preconceitos se encontramos inúmeros grupos de dança e trios elétricos onde são formados por homens durante 0 carnaval. Nas danças de salão que o Brasil exporta, nas danças de ruas; capoeira; entre outras situações que a dança não está associada ao corpo delicado da bailarina clássica, mas ao contrário, a virilidade, a força, a identidade cultural do homem brasileiro.

A pesquisa identificou que o ensino de dança, como conteúdo da Educação Física, no Ensino Fundamental II, é relegado a um segundo plano, mesmo que haja o reconhecimento da sua contribuição na formação do sujeito. '̂̉e reconhecemos a Dança como conteúdo, teremos que recorrer a ela, assim como recorremos aos demais conteúdos como sendo importantes para a formação das crianças e adolescentesò(BRASILEIRO, 2002, p. 09). 
O quadro 7 apresenta as dificuldades dos professores para trabalharem com o ensino de Educação Física, no Ensino Fundamental II:

\begin{tabular}{|c|c|}
\hline SUJEITO DA PESQUISA & RESPOSTAS \\
\hline S1 & $\begin{array}{l}\text { Empecilhos é alguns alunos não querer fazer, diminui a quantidade de alunos, são empecilhos porque podia } \\
\text { estar todo mundo participando e as vezes por eles não gostar, eles não participam, desafios são isso. É a } \\
\text { gente mostrar que tem outras modalidades que podem ser trabalhadas com eles também estuda para } \\
\text { formação deles [sic]. }\end{array}$ \\
\hline S2 & Os empecilhos são as brigas muitas intrigas nas aulas [sic]. \\
\hline S3 & $\begin{array}{l}\text { Os principais empecilhos e a falta de oportunidade no mercado de trabalho e os desafios maior são esses... } \\
\text { a gente buscar espaço no campo de trabalho [sic]. }\end{array}$ \\
\hline
\end{tabular}

Os exercícios físicos na forma cultural de jogos, ginásticas, danças, equitação surgem na Europa no final do século XVIII e início do século XIX. Esse é o espaço/tempo da formação dos sistemas nacionais de ensino característicos da sociedade burguesa daquele período (SOARES et al., 1992).

Naquela época os exercícios físicos passaram a ser entendidos como receita médica, para desenvolver e fortalecer física e moralmente os indivíduos. Portanto, uma das funções a serem desempenhadas pela Educação Física no sistema educacional, e uma das razões para a sua existência. As aulas de Educação Física nas escolas eram ministradas por instrutores físicos do exército, que traziam para essas instituições os rígidos métodos militares da disciplina e da hierarquia (SOARES et al., 1992).

Brasileiro (2008) explicita que a presença histórica da dança como conteúdo da Educação Física remota ao final do século XIX, foi associada ao ensino das ginásticas, que ora se configura como Educação Física, compondo a tríade educação moral, intelectual e física, que constituíam um conjunto de conhecimentos necessários à educação do homem brasileiro, numa perspectiva civilizatória e moderna.

A orientação pedagógica para justificar a presença da dança no currículo escolar era recomendada pelo seu uso que, r̃ Caberia às exercitações, para a melhoria da postura e a eficiência de seus gestos, a dança feita pelos militares, danças de organização de combates ou as danças reconhecidas na sociedade, as danças oriundas dos salões da nobrezaò (BRASILEIRO, 2008, p. 521).

Por outro lado, eram $\tilde{n}$...] desconsideradas todas as danças de rua, ou as que chegavam aos palcos públicos, aquelas de buscavam o riso, o inoportuno, o desgaste do movimento, aquelas que feitas nas ruas ou nos circos abusavam do uso dos gestos, aquelas 
saltitantes, em que mulheres e homens desperdiçavam energiaò (BRASILEIRO, 2008, p. 521).

A concepção de Educação Física como uma ñpráticaò ainda parece residir, nos dias atuais e no cotidiano das aulas. O professor enfrenta desafios diários para implantar uma prática pedagógica que vislumbre e inclua as diversas manifestações da cultura corporal. Há que se reconhecer a questão da prática pedagógica em Educação Física marcada pelo trato com o corpo como objeto/instrumento de rendimento físico voltado à performance atlética.

Estes aspectos forneceram ñpistasòpara compreensão das resistências e dificuldades do ensino de dança, como conteúdo da Educação Física, no Ensino Fundamental II, conforme falas abaixo:

\begin{tabular}{|l|l|}
\hline SUJEITO DA PESQUISA & RESPOSTAS \\
\hline S1 & $\begin{array}{l}\text { Vergonha de alguns alunos não querer fazer ...vergonhas de se expor as poucos alunos gostam não } \\
\text { todo mundo que gosta ai dificultam que é um dois que gostam de uma sala outro é da outra e acaba } \\
\text { dificultando [sic]. }\end{array}$ \\
\hline S2 & As brincadeiras dificultam muito eles fazem umas brincadeiras que não tem lógica [sic]. \\
\hline S3 & $\begin{array}{l}\text { Bom primeiramente o conteúdo Dança nas aulas de Educação Física não é praticada não só por causa } \\
\text { do aluno o professor as vezes também deixa a desejar nessa parte, também os interesses do aluno os } \\
\text { alunos não são muito interessado em dança eles ainda prefere as práticas do esportes como futebol, } \\
\text { vôlei, basquete, handebol e também o conteúdo da dança nas aulas é muito difícil você aplicar dança } \\
\text { nas aulas de educação física[sic]. }\end{array}$ \\
\hline
\end{tabular}

Quadro 8 - As dificuldades do ensino da dança na Educação Física, no Ensino Fundamental II, na rede estadual de São José dos Quatro Marcos - MT.

Nota: Construção das autoras.

Tal como Strazzacappa (2001) a pesquisa identificou que um dos fatores que tem limitado a presença e o ensino da dança na escola é a receptividade dos próprios professores da escola. A autora registra que, ñAlguns tendem a m̃menosprezaròo trabalho, considerando a dança um ñuxoòde menor importância no conjunto das disciplinas oferecidas pelo currículo. ̃̃A segunda barreira diz respeito a um outro tipo de preconceito, desta vez não do professor, mas do próprio alunoò(STRAZZACAPPA, 2001, p. 74).

Marques (2007) aponta também, que as dificuldades para o ensino da dança na escola está relacionada à concepção de escola, que $\tilde{\eta}[. .$.$] há séculos tem valorizado o$ conhecimento analítico, descritivo e linear em detrimento do conhecimento sintético, sistêmico, corpora, intuitivoò Assim, r̃os processos de criação em dança acabam não se encaixando nos modelos tradicionais de educaçãoò(MARQUES, 2007, p. 18).

Brasileiro (2002) percebeu que a dança não é tratada como conteúdo nas aulas de Educação Física, apesar de aparecer em festividades e datas comemorativas. A ausência do ensino sistemático de dança na escola é justificado pela não aceitação dos alunos, especialmente do sexo masculino, entre outros. 
A respeito do sexismo em relação à dança, Pacheco (1999, p. 09) afirma que ñA dança nas aulas de educação física pode contribuir para que acabemos com concepções fechadas e restritas de masculinidade/feminilidade, bem como para que respeitemos as opções individuaisò mesmo não sendo esta sua tarefa principal, que precisa ser trabalhada no cotidiano da escola por todos os agentes de ensino e disciplinas do currículo escolar.

A autora propõe que 0 ensino de dança aproveite as diversas [n]...] possibilidades dinâmicas do movimento (o delicado e o bruto, o forte e o fraco, o leve e o pesado, entre outras), de modo a rompermos com associações e estigmas sexistas e homofóbicosò (PACHECO, 1999, p. 08). E, discorda de experiências com dança que se preocupam em ṇ̃...] suavizar homens ou de embrutecer mulheresò ao valorizar a experiência com [ị...] ambas as situações independentemente do sexo e da orientação sexual da pessoaò(PACHECO, 1999, p. 09).

\section{CONSIDERAÇÕES FINAIS}

O estudo teve como foco de reflexão a escola e as possibilidades de intervenção pedagógica com a dança, como conteúdo das aulas de Educação Física, no Ensino Fundamental II. Em específico, se propôs a refletir os limites e (im)possibilidades para o ensino de dança, vinculando-se à formação humana do aluno, ao identificar o f̃ugaròque tem ocupado no currículo escolar e os desafios para que se alcance uma formação em dança, que supere o tradicional ensino de passos e coreografias ensaiadas muitas vezes até a exaustão dos alunos para apreciação pública em momentos festivos da escola, desprovida de uma contextualização crítica sobre o movimento.

As dificuldades para a implantação e o ensino contínuo de dança, no currículo da Educação Física, incluem: a formação profissional insuficiente para qualificação do ensino de dança; a presença de estereótipos em relação ao ato de dançar, intermediados por questões de gênero; a compreensão unilateral da dança como instrumento auxiliar para o desenvolvimento motor; a r̃̃rençaòde que se trata de um conteúdo de segunda ordem a ser trabalhado em momentos festivos na escola; e não menos importante, a compreensão da Educação Física como prática esportivizada.

A investigação contribui para ampliação da discussão da importância do desenvolvimento de propostas de ensino, que tenham a dança como conteúdo, de caráter 
perene, numa perspectiva emancipatória que ultrapasse a dimensão técnica-procedimental da aprendizagem do movimento. Fato esse, que indica a importância da qualificação da formação de professores como condição para a presença do ensino de dança na Educação Física Escolar.

\section{REFERÊNCIAS}

BRASIL. Secretaria de Educação Fundamental. Parâmetros Curriculares Nacionais: Educação Física/Secretaria de Educação Fundamental. Brasília: MEC/SEF, 1998.

BRASILEIRO, L. T. O conhecimento no currículo escolar: o conteúdo dança em aulas de Educação Física na perspectiva crítica. In: Revista Movimento, v. 8, n. 3. Porto Alegre: UFRGS, 2002. p. 5-118.

BRASILEIRO, L. T. O ensino da dança na Educação Física: formação e intervenção pedagógica em discussão. In: Motriz, v. 14, n. 4, out./dez. Rio Claro: UNESP, 2008. p. 519528.

DARIDO, S. C.; RANGEL, I. C. Educação Física na escola: implicações para a prática pedagógica. Rio de Janeiro: Guanabara Koogan, 2005.

DAVID, N. A. N. A formação de professores para a Educação Básica: dilemas atuais para a Educação Física. In: Revista Brasileira de Ciências do Esporte, v. 23. n. 02. Campinas: Autores Associados, 2002. p.119-133.

GARIBA, C. M. S. e FRANZONI, A. Dança Escolar: uma possibilidade na Educação Física. In: Revista Movimento, v. 13, n. 02. Porto Alegre: UFRGS, 2007. p. 155-171.

MARQUES, I. A. Dançando na escola. 4. ed. São Paulo: Cortez, 2007.

PACHECO, A. J. P. Educação Física e Dança: uma análise bibliográfica. In: Revista Pensar a Prática, v. 2, jun.-jul. Goiânia: UFG, 1998-1999. p. 156-171.

PICCOLI, J. C. J.; MENEZES, F. C. L. de. O perfil do egresso do Curso de Educação Física do Centro Universitário Feevale. In: Revista Digital EFDeportes. Buenos Aires, ano 11, n. 98, Jul./2006. Disponível em:<http://www.efdeportes.com/efd98/feevale.htm>_Acesso em: 10 de janeiro de 2011.

SOARES, C. L. et al. Metodologia do ensino de Educação Física. São Paulo: Cortez, 1992.

STRAZZACAPPA, M. A Educação e a fábrica de corpos: a dança na escola. 2001. 


\title{
DIFFICULTIES AND CHALLENGES FOR DANCE EDUCATION IN PHYSICAL EDUCATION CLASSES, IN THE ELEMENTARY SCHOOL II
}

\begin{abstract}
Pedagogical difficulties are investigated that Physical Education teachers face in teaching dance in the Secondary School, in S. J. dos Quatro Marcos/MT/Brazil. The study is qualitative and descriptive. Interview guide was applied semi-structured with three teachers, organized in: a) personal profile; b) vocational training; c) professional activities; d) the dance education. We found data on vocational training of teachers; the presence of stereotypes about dance as part of the educational training; and pedagogical difficulties. The research contributed to the discussion dance an emancipatory perspective, going beyond a technical-procedural dimension of movement learning.
\end{abstract}

KEYWORDS: Dance. Physical Education. Elementary Education II.

\section{DIFICULTADES Y DESAFÍOS PARA LA EDUCACIÓN DE LA DANZA EN CLASES DE EDUCACIÓN FÍSICA, EN LA ESCUELA PRIMARIA II}

\begin{abstract}
RESUMEN
Dificultades Pedagógicas son investigados que los profesores de Educación Física se enfrentan en enseñanza de la danza en la Escuela Secundaria, en dos S. J. Quatro Marcos/Brasil. El estudio es cualitativo y descriptivo. Guía de entrevista se aplicó semiestructurada con tres profesores, organizados en: a) perfil personal; b) la formación profesional; c) la actividad profesional; d) la enseñanza de la danza. Encontramos datos sobre la formación profesional de los docentes; la presencia de estereotipos acerca de la danza como parte de la formación educativa; y dificultades pedagógicas. La investigación contribuyó a la discusión bailar una perspectiva emancipatoria, yendo más allá de la dimensión técnico-procesal de aprendizaje movimiento.
\end{abstract}

PALABRAS CLAVE: Dance. Educación Física. Educación Primaria II. 